\title{
EFFECTIVE OPTIONS FOR DETERMINING CUSTOMER PROFITABILITY
}

\author{
Venelin TERZIEV, Vanya BANABAKOVA, Marin GEORGIEV \\ "Vasil Levski" National Military University, Veliko Tarnovo, Bulgaria \\ terziev@skmat.com
}

\begin{abstract}
Marketing is an art to attract and retain customers, but not to any but profitable customers. Unfortunately, organizations often understand that 20 to 40 percent of their customers are unprofitable. Also, many organizations report the fact that their most profitable customers are not the ones who buy the most, but the average shoppers. Major customers require special service and get the biggest discounts, thus reducing the company's profits. The smallest customers pay the full price and get a minimum of service, but the expenses connected with the deals reduces the profitability they earn. Average customers enjoy good service, pay almost the whole price, and in many cases prove to be the most profitable. Therefore, a number of large organizations, which initially target only large customers are then orientated towards the average customer market. An organization should not pursue and satisfy every client. Orientation should be to cost-effective customers. This in turn requires the definition of a "cost-effective customer". The present study explores the possibilities for measuring customer profitability, analyzes the connection- service' expenses, a cost-effective client and presents the application of the $A B C$ method - analysis to distinguish the customer service policy.
\end{abstract}

Keywords: customer, customer profitability, customer service's expenses, ABC-analysis.

\section{Introduction}

Marketing is the art of attracting and retaining customers, but not just any, but profitable customers. Unfortunately, organizations often understand that 20 to 40 percent of their customers are unprofitable. Also, many organizations report the fact that their most profitable customers are not the ones who buy the most, but the average shoppers.

Major customers require special service and get the biggest discounts, thus reducing the company's profits.

The smallest customers pay the full price and get a minimum of service, but the cost for their transactions reduces the profitability they earn.

Average customers enjoy good service, pay almost the whole price, and in many cases prove to be the most profitable. Therefore, a number of large organizations, which initially target only large customers, are then oriented towards the average customer market.

An organization should not pursue and satisfy every client.

Some organizations are trying to do whatever customers offer. Although customers often make very good suggestions, they sometimes offer quite inadequate and unprofitable suggestions for the organization. Random compliance with them may divert the organization from its market focus. That is why a strict selection of the clients to be serviced and careful consideration of the respective combination of benefits and prices to be offered will be required.

Orientation should be to cost-effective customers. This in turn requires the 
definition of a "cost-effective customer". The purpose of the present study is to explore the possibilities of measuring the profitability of customers, to analyze the relationship between service costs - a costeffective customer and to present the application of the $\mathrm{ABC}$ method - analysis for differentiation of the customer service policy. [1]

\section{Determining the profitability of the customer}

According to Philip Kotler, a cost-effective customer is a person, a household, or a company that earns revenue over a certain period of time, and the contribution exceeds the company's costs of attracting, persuading, purchasing, and servicing.

Attention should be paid to the profits and costs that the customer carries to the organization for a long time rather than a specific purchase.

The fact is that most organizations do not pay attention to the customer's profitability. It is advisable to improve this activity by first applying the following model for profitability analysis (Table 1.).

Table 1. Analysis of the profitability of the client-product relationship

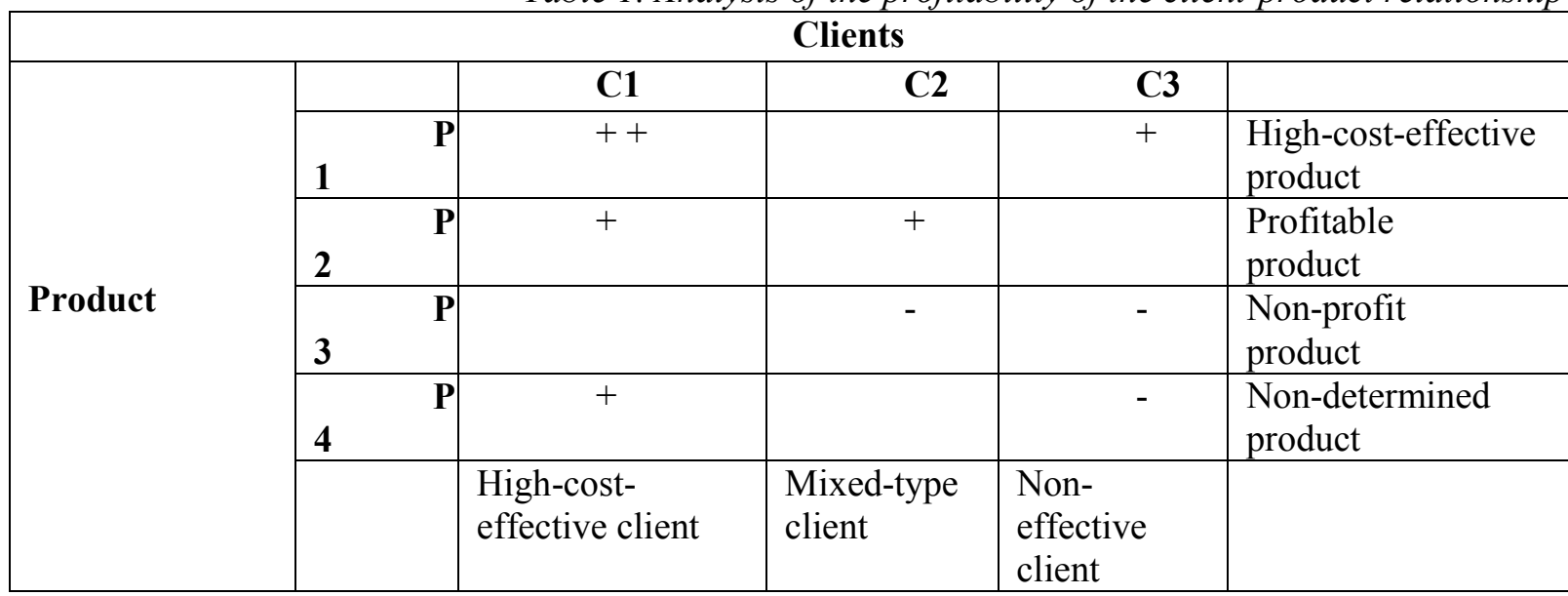

In the model, customers are stacked in columns, and products in rows. Each square has an indication of the profitability of the sale of the given product to the designated customer. It is clear that customer 1 is very cost-effective because it buys three costeffective products - P1, P2 and P4. Client 2 presents mixed profitability, as it buys a cost-effective and unprofitable product. Client 3 is at a loss for the organization because it buys one profitable and two unprofitable products.

Based on this model, the question arises as to what the organization can do in this situation.

First - It can raise the price of the more unprofitable products or eliminate them.

Second - It can try to transfer cost-effective products to unprofitable clients. If these customers decide to leave, this may be good. In fact, it can be argued whether it may turn out to be more profitable for an organization to encourage the dropping off of its unprofitable clients.

One of the main issues that traditional cost reporting procedures can hardly answer is how much is a client's income greater than the income earned by another. Organizations typically calculate customer returns only on the basis of gross profit. In other words, from the revenue generated by a customer they subtract the full cost (full cost) of the goods sold. In practice, however, there are still many costs that need to be taken into account before calculating the real yields of each particular client. The same is true when the profitability of a market segment or distribution channel has to be disclosed. The magnitude of costs for customer 
service depends entirely on how the organizational strategy will be designed. The analysis of customer returns shows that often some customers have a negative contribution. Grouping of customers should be done according to the $\mathrm{ABC}$ analysis methodology. Reasons for different yields are due to the fact that customer service costs can vary considerably, whether they buy the same or different quatities of company output.

Service expenses start with the order itself. They can be identified by determining: the time spent by the sales agent for the client concerned; Is there a responsible manager whose time is spent wholly or partly on the client concerned? What commission you will have to pay for this sale, and more.

Costs then arise for the construction (completion) of the order, which differ from each other according to the number of desired modifications in the order and their complexity. Add to them the costs of transport, safe-keeping and storage. Besides, there are additional costs associated with product packaging according to customer's desire.

It is a common situation for the supplier company to organize special cash funds for some clients. They are spent on joint incentives to promote sales, product advertising, additional sales concessions, and more. If a trader decides to promote sales of a particular type of product through a special packaging, this may result in additional hidden costs for the supplier.

They result from a number of reasons such as: violating the business plan of the supplier enterprise; maintaining additional inventory of the particular product and others. Typically, this type of spending is very rarely reported for each specific customer, so they have an implicit character.

One of the basic principles for customer return analysis, which the provider must apply, is to disclose and describe all customer-specific costs. A useful way to uncover these costs is to determine which costs will be dropped if the customer is discontinued.

A major advantage of the principle of dropping costs is that much of the cost of customer service is actually distributed among several. For example, the distribution warehouse is a good confirmation of this claim. If the supplier uses the storage space for other purposes, then it will be incorrect to allocate part of the total warehouse cost to only one customer.

An indicative list of costs is presented in Table 2, which is an integral part of the client's profitability statement. The costs thus incurred inherent in the respective customer should be deducted from the revenue (net income from sales).

Table 2. Operative profitability report

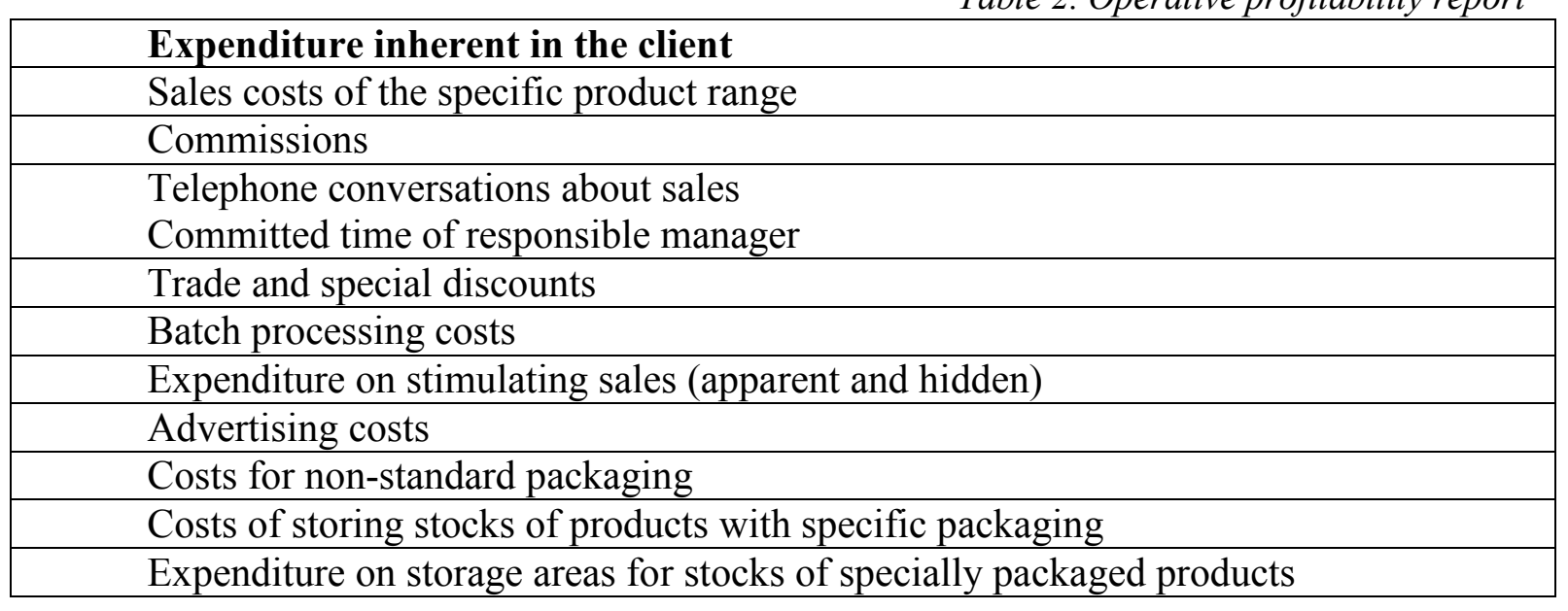




\begin{tabular}{|l|}
\hline Warehouse handling costs \\
\hline Transport costs \\
\hline Documentation and communication costs \\
\hline Expenditure on returned or refused items \\
\hline Commercial credit \\
\hline
\end{tabular}

If the activity of the organization is linked to many clients, it would not be profitable to perform a separate analysis of the profitability of each of them. In this case, it is best to select those clients who are representatives of certain similar segments of their characteristics. This will give us a quicker view of the relative costs associated with a particular type of customer, market segment, or distribution channel.

An application is a baseline model for reporting the contribution of each customer who can target when disclosing those costs that are directly related to a particular customer or group of clients. This gives an opportunity to assess which of the costs would be dropped in case of discontinuing contacts with a client or it would be lost due to competition on the part of other companies.

Starting point for the model is the gross revenue generated by the execution of a specific order. From them we deduct all discounts that are made for that particular customer and the order. This results in the net revenue from the sale of the items in the order. Accordingly, from net revenues we deduct direct production costs. Indirect costs are included in the calculations only when they are absolutely related to the particular client. Similarly we proceed with the cost of sales and marketing.

After subtracting the inherent distribution costs, the gross contribution (income) of the respective customer is obtained. Finally, all other costs that are directly related to the buyer are deducted, such as trade credits, returned or declined products, and others. The resulting balance represents the socalled net contribution of the client. It shows how much the customer contributes to covering the company's fixed costs and how much they help to realize the company's profits.

However, if the analysis continues with attempts to distribute the company's fixed costs to the client, a fictitious image of its yield can be generated. The allocation of fixed costs to different orders (clients) is considered an incorrect approach as it generates many problems and leads to mistaken decisions. However, as long as the net contribution of a client has a positive value and there are no other "alternative costs" of service, the organization has a greater interest in the customer being detained rather than rejected.

The information of the size of net contribution can be used in the following directions:

-When negotiating a particular order.

- As a basis for developing the marketing strategy of the company, which will direct it towards a more profitable business.

- Developing alternative management strategies for the customers with high logistics costs.

The ideal case for any organization is for all its clients to be profitable in the medium and the long term. In this regard, appropriate ways of retaining and furthering the profitability of these buyers, which bear the organization's current profit, should be sought. [2]

\section{Model for differentiated servicing of market segments based on $\mathrm{ABC}$ analysis.} Customers differ in several important points: what they buy, how much they buy, what schedule their purchases follow, what delivery times for the ordered goods they require and others.

Customer differentiation on these and other signs can serve to determine strategy and 
operational decision-making related to service. The purpose of differentiation is to establish which goods and services and which customers are more and less profitable for the company and depending on this to define the policy in servicing different categories of customers and in selling goods and services with different participation in sales and profits.

In this sense, $A B C$ analysis is a very good method for such differentiation. For the purpose of service management, the $\mathrm{ABC}$ analysis should be implemented in two stages:

In the first stage, the product groups and their varieties are classified according to their participation in the volume of sales and in the profit realized. Most often, the classification is done in three groups, but more groups can be divided.

Group A includes products and assortment varieties that have the largest share in sales volumes and profits. They are most often in demand and are bought in large quantities by relatively constant customers. Their assortment varieties are usually not large, but sales are high, so stock turnover is the largest and their size is small.

Group B includes products and assortment varieties with a smaller share of sales volumes, a larger range of interchangeable varieties, and therefore larger stocks of goods should be maintained to ensure a high level of service for the customers.

Group C includes products and assortment varieties with the smallest share of sales volumes, a wide variety of assortment varieties, a slow stock turnover, and therefore larger stockpiles need to be maintained to maintain the desired level customer service. These commodity groups are the least profitable for the company, but their offering gives customers the impression of a wide variety of selection and opportunities for a wide choice. It is possible that this group also includes lowpriced goods that are purchased by customers with lower solvency.

According to this logic, several groups of goods can be differentiated according to the two criteria: relative share in sales and relative share in the realized profit.

In the second stage, customers should be categorized according to the product groups they buy and the respective quantities.

Customers who regularly buy large quantities of goods mainly from Group A are most profitable for the company because they contribute to the realization of the bulk of sales and profits.

The most unprofitable for the company are the customers who buy small quantities of the most unprofitable groups - $\mathrm{C}$ and other. Typically, such customers are the most numerous and the company can't give up from servicing them. However, it will not set the same conditions for servicing this category of customers as compared to customer service in the first category.

$\mathrm{ABC}$ analysis allows us to rank goods and customers and find the most appropriate combinations. Profitable combinations are those in which customers in the first category buy Group A products or the combination of first-class and C-group products. For the next combinations, sales volume and profitability declines until we reach the losing combination of customers, who buy small quantities and are looking for low-priced products, but with greater choice and substitutability.

The main task of service management is to win customers - to buy more, to return for new purchases and to attract new customers. This can be achieved by offering an optimal order fulfilment cycle, by maintaining a stock level to ensure security of order execution, and by providing additional free and payable services, differentiating service delivery. [2, 3-4]

\section{Conclusions}

In conclusion, the measurement of customer profitability and their differentiation, as well as the differentiation of the product groups sold by the organization, makes it possible to adopt and carry out a differentiated service policy 
mainly on the following elements: order fulfillment cycle; the level of supported commodity stocks, depending on the demand and the contribution to the realization of the profit; minimum quantities to order from individual commodity groups; extending the delivery time with the required consolidation time (merging small consignments) for shipments to customers; choosing the type of transport when shipment is provided by the supplier as well as geographic territories, distribution channels and product lines, and others.

Management should inform all employees and those responsible for sales, how to achieve the objectives of customer service. [5-6]

\section{References}

[1] Terziev, V., Banabakova, V., Georgiev, M., Customer's Profitability Analyses and Customer Service Policies, Journal of Innovations and Sustainability, Innovations and Sustainability Academy, Vol. 3, N 3, pp. 39-48, 2017.

[2] Terziev, V., Banabakova, V., Marketing, Institute of Knowledge Management, Skopje, Macedonia, p. 107, 2017.

[3] Terziev, V., Banabakova, V., Stefanov.S., Georgiev, M., Study of consumer behavior, Fifteenth International Scientific Conference: Knowledge in practice, Bansko, Bulgaria, International Journal of Knowledge and Learning, Institute of Knowledge ManagementSkopje, Vol. 20, N1, pp.465-471, 2017.

[4] Terziev, V., Banabakova, V., Stefanov, S., Georgiev, M., Evolution of the marketing concept, marketing mix -,,mix of components“ or a set of actions, Fifteenth International Scientific Conference: Knowledge in practice, Bansko, Bulgaria, International Journal of Knowledge and Learning, Institute of Knowledge ManagementSkopje, Vol. 20, N1, pp. 213-218, 2017.

[5] Terziev, V., Banabakova, V., Georgiev, M., Possibilities for determining customer's profitability, Proceedings of INTCESS 2018- 5th International Conference on Education and Social Sciences 5-7 February 2018- Istanbul, Turkey, 2018, pp. 438-444.

[6] Terziev, V., Banabakova, V., Georgiev, M., Customer service standards, Proceedings of INTCESS 2018- 5th International Conference on Education and Social Sciences 5-7 February 2018- Istanbul, Turkey, 2018, pp. 431-437. 